\title{
Novel aggrecan variant, p. Gln2364Pro, causes severe familial nonsyndromic adult short stature and poor growth hormone response in Chinese children
}

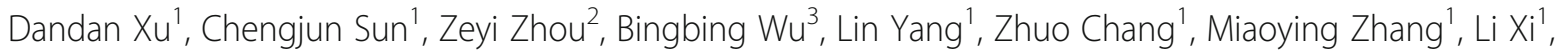
Ruoqian Cheng ${ }^{1}$, Jinwen $\mathrm{Ni}^{1}$ and Feihong Luo ${ }^{1 *}$ (B)

\begin{abstract}
Background: Mutations in the aggrecan (ACAM) gene can cause short stature (with heterogeneous clinical phenotypes), impaired bone maturation, and large variations in response to growth hormone $(\mathrm{GH})$ treatment. For such cases, long-term longitudinal therapy data from China are still scarce. We report that a previously unknown ACAN gene variant reduces adult height and we analyze the $\mathrm{GH}$ response in children from an affected large Chinese family.

Methods: Two children initially diagnosed with idiopathic short stature (ISS) and a third mildly short child from a large Chinese family presented with poor GH response. Genetic etiology was identified by whole exome sequencing and confirmed via Sanger sequencing. Adult heights were analyzed, and the responses to GH treatment of the proband and two affected relatives are summarized and compared to other cases reported in the literature.

Results: A novel ACAN gene variant c.7465 T > C (p. Gln2364Pro), predicted to be disease causing, was discovered in the children, without evident syndromic short stature; mild bone abnormity was present in these children, including cervicalvertebral clefts and apophyses in the upper and lower thoracic vertebrae. Among the variant carriers, the average adult male and female heights were reduced by -5.2 and -3.9 standard deviation scores (SDS), respectively. After GH treatment of the three children, first-year heights increased from 0.23 to 0.33 SDS (cases in the literature: -0.5 to 0.8 SDS), and the average yearly height improvement was 0.0 to 0.26 SDS (cases in the literature: -0.5 to 0.9 SDS).

Conclusions: We report a novel pathogenic ACAN variant in a large Chinese family which can cause severe adult nonsyndromic short stature without evident family history of bone disease. The evaluated cases and the reports from the literature reveal a general trend of gradually diminishing yearly height growth (measured in SDS) over the course of $\mathrm{GH}$ treatment in variant-carrying children, highlighting the need to develop novel management regimens.
\end{abstract}

Keywords: Aggrecan, ACAN gene, Short stature, Adult height, Growth hormone

\section{Background}

Human linear growth is a complex process determined primarily by genetic factors and modulated by environmental factors [1]. Based on its etiology, short stature can be divided into primary growth disorder, secondary growth disorder, and idiopathic short stature (ISS) [2, 3].

\footnotetext{
* Correspondence: luofh@fudan.edu.cn

'Department of Pediatric Endocrinology and Inherited Metabolic Diseases,

Children's Hospital of Fudan University, 399 Wan Yuan Road, Minhang

District, Shanghai 201102, China

Full list of author information is available at the end of the article
}

ISS refers to short stature with no apparent cause and is often described as either sporadic cases or familial short stature [2]. With the development of sequencing technologies, ISS has been found, in some patients, to be caused by mutations in genes involved in the hypothalamicpituitary-growth hormone $(\mathrm{GH})$ axis, such as $G H 1, G H R$, and GHRHR (GHRH receptor) [4-7]. Genetic defects in the $\mathrm{GH}$ axis only constitute a small fraction of clinically diagnosed short-stature cases [8]. Defects in growth height are probably associated with other yet-to-be-identified genes [9].

(c) The Author(s). 2018 Open Access This article is distributed under the terms of the Creative Commons Attribution 4.0 International License (http://creativecommons.org/licenses/by/4.0/), which permits unrestricted use, distribution, and reproduction in any medium, provided you give appropriate credit to the original author(s) and the source, provide a link to the Creative Commons license, and indicate if changes were made. The Creative Commons Public Domain Dedication waiver (http://creativecommons.org/publicdomain/zero/1.0/) applies to the data made available in this article, unless otherwise stated. 
Recent studies found that ACAN (MIM 155760, NM 013227.3) mutations are associated with accelerated bone maturation and progressive growth failure $[4,10]$. In a prospective clinical study of 290 patients born small for gestational age (SGA) with short stature [11], four patients were identified as carrying heterozygous $A C A N$ mutations and showed large variation in response to $\mathrm{GH}$ treatment. A recent study indicated that $A C A N$ mutations are associated with short stature without syndromic manifestations [12]. However, studies on the relationship between $A C A N$ gene mutations and adult height are scarce, and the reported data are typically from small family pedigrees. Thus, the optimal management of child mutation carriers remains unclear. We have analyzed the effects of an $A C A N$ variant on adult height, based on data from one large Chinese family. In addition, we report the affected children's response to $\mathrm{GH}$ treatment and summarize the effects of $\mathrm{GH}$ treatment on individuals with $A C A N \mathrm{mu}$ tations reported in the literature.

\section{Methods}

\section{Subjects and diagnosis}

This study was approved by the Hospital Ethics Committee of the Children's Hospital of Fudan University. Three children from the same large family, comprising 90 members, were recruited. Two of the children (Fig. 1. IV:23 and IV:44) were initially referred to us due to their short statures, according to the growth charts for Chinese children and adolescents aged 0 to 18 years [13]. Normal GH secretion in both children was confirmed by a peak of GH $\geq 10 \mathrm{ng} / \mathrm{mL}$ in insulin or arginine provocative tests. After evident physical deformities and organic etiologies were excluded, the primary diagnosis of ISS was made according to the diagnosis consensus [3]. The third child, for whom an initial height record was lacking, had height (Fig. 1. III:21) -0.88 standard deviation score (SDS) from the same family and had received 1 year of GH therapy before being referred to our clinic. We initiated $\mathrm{GH}$ therapy in these three children at a dose between 40 and $60 \mu \mathrm{g} / \mathrm{kg} / \mathrm{d}$ and titrated to maintain serum IGF-1 levels between the average and +2 standard deviations (SDs) of the reference [3]. All three children showed a poor response to $\mathrm{GH}$ treatment according to the criterion of SDS $<0.5$ proposed by Patel and Clayton [14]. Therefore, the three children and their family members were offered genetic testing. Among the 90 family members, 62 subjects were available.

\section{Whole exome sequencing}

Whole exome sequencing was performed with genomic DNA extracted (QIAamp DNA Blood Mini kit, Qiagen, Germany) from subjects' blood samples. Exomes were enriched with Illumina's SureSelect Human All Exon kit $\mathrm{V} 4$, targeting $50 \mathrm{Mb}$ of sequence from exons and flanking regions. Sequencing was performed with the Illumina HiSeq 2000 platform. Reads with adaptors, reads with $>10 \%$ of unknown bases (Ns), and low-quality reads with $>50 \%$ of low-quality bases (i.e., bases with a sequencing quality of 5 or less) were discarded from the raw data to generate clean reads, 90 -bp paired-end and with at least 100 -fold average sequencing depth. Clean reads were aligned to the reference human genome (UCSC hg19) by using the Burrows-Wheeler Aligner (BWA) (v.0.5.9-r16). Subsequent processing steps of sorting, merging, and removing duplicates for the BAM files were performed by using SAMtools and Picard (http://broadinstitute.github. io/picard/). Mutation calls, which differed from the reference sequence, were obtained with the use of GATK. Mutations were annotated by ANNOVAR and VEP software $[15,16]$. Mutations with suboptimal quality scores were removed from consideration. The remaining mutations were compared computationally with the list of reported mutations from the Human Gene Mutation Database (HGMD, professional version). Mutations in this database with minor allele frequency $<5 \%$ according to either the 1000 Genomes Project or ExAC data of The Exome Aggregation Consortium (http://exac.broadinstitute. org/) were retained. For changes that were not represented in the HGMD, synonymous mutations, intronic mutations that were $>15$ bp from exon boundaries (which are unlikely

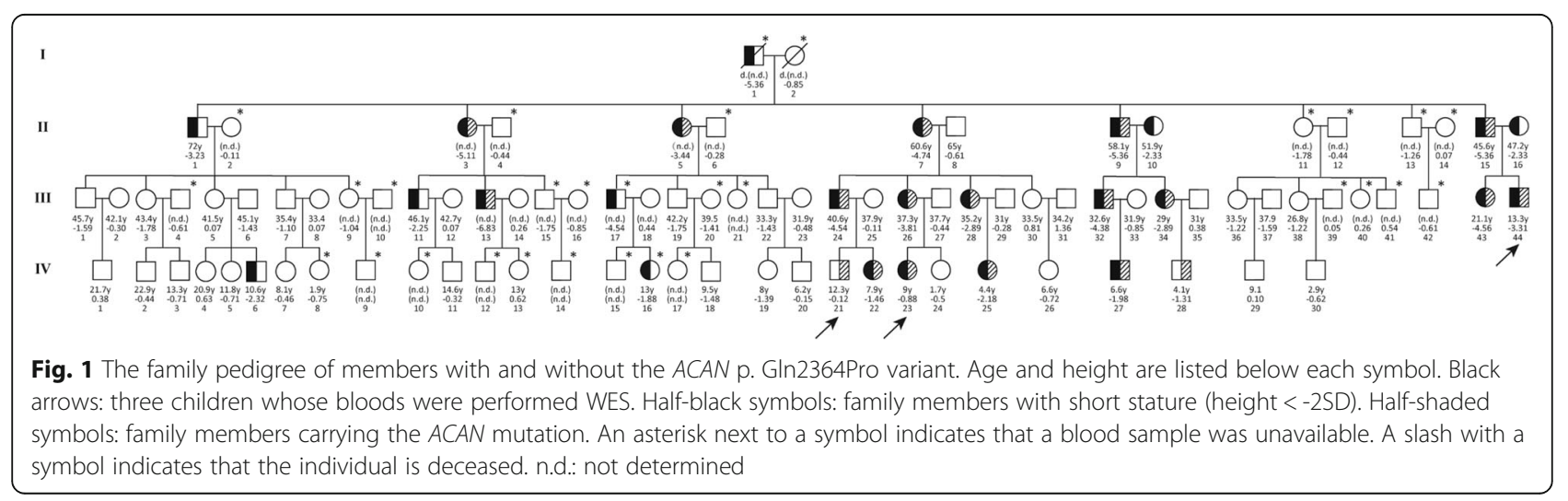


to affect messenger RNA splicing), and common mutations (minor allele frequency $>1 \%$ ) were discarded $[15,16]$.

\section{Bioinformatics assessment of variant function}

To assess the effects of the variant, we conducted analyses using SIFT, PolyPhen-2, and MutationTaster software, to predict possible deleterious effects [17-19]. In addition, we performed conservation analysis, using the PhyloP score embedded in the USCS genome browser [20]. Three-dimensional models of aggrecan protein were produced by SWISS-MODEL SERVER [21].

\section{Variant confirmation by sanger sequencing}

After the identification of an $A C A N$ variant in family members, we performed Sanger sequencing on PCR products containing the variant (in exon 14). The purified DNA was used as template for PCR amplification. The reaction mixture $(20 \mu \mathrm{L})$ contained $50 \mathrm{ng}$ DNA; $1 \mathrm{U}$ Taq DNA polymerase (Promega, USA); $1.5 \mathrm{mM} \mathrm{MgCl}_{2}$; $0.25 \mathrm{mM}$ each $\mathrm{dNTP}$; and $0.5 \mu \mathrm{M}$ primers. The primers for the amplification of $A C A N$ were as follows: $A C A N$ Forward: CATCTGCCATCCCCTGGT, ACAN-Reverse: CCTACACCGCCACTCTCCTC. The thermal cycling conditions for the PCR reactions consisted of an initial denaturation step at $95{ }^{\circ} \mathrm{C}$ for $5 \mathrm{~min} ; 35$ cycles of denaturation at $95{ }^{\circ} \mathrm{C}$ for $30 \mathrm{~s}$, primer annealing at $58{ }^{\circ} \mathrm{C}$ for $30 \mathrm{~s}$, and extension at $72{ }^{\circ} \mathrm{C}$ for $30 \mathrm{~s}$; and a final step at $72{ }^{\circ} \mathrm{C}$ for $7 \mathrm{~min}$. The PCR products were sequenced in an ABI sequencer $3500 \mathrm{xL}$ GA (Applied Biosystems). The sequence data were evaluated using Mutation Surveyor software and compared with the reference sequence of ACAN (NM_001135).

\section{Family members}

After identification of $A C A N$ variant in the three children who came to our clinic, we invited all family members to participate in our study; the pedigree is shown in Fig. 1. Genotyping and collection of basic information (height, age, and history of bone disorders) in the adult family members were conducted after obtaining informed consent from the subjects. For persons younger than $18 \mathrm{y}$, informed consent was obtained from the parents.

\section{Measurement of responses to growth hormone treatment} During GH treatment of the three children, we measured the levels of serum IGF-1 and IGF-binding protein 3 (IGFBP3) every three or six months by solid-phase, two-site chemiluminescent immunometric assay via an automated MMULITE 1000 immunoassay system (Siemens, Munich, Germany).

\section{Statistical analysis}

Height, body mass index (BMI, weight $(\mathrm{kg})$ divided by the square of the height $(\mathrm{m})$ ), and bone age (GP atlas) were measured. SDS values for height and BMI were calculated using national references. We used a t-test (SPSS Version 17.0) to compare the differences in height between family members with and without the $A C A N$ variant.

\section{Results \\ ACAN variant and functional in silico prediction}

Whole exome sequencing to a median of $150 \times 125.47$ (125.47 165.65) coverage in the index patients identified 825,823 genetic variants of which 119 were not found in dbSNP137, ExAC, the 1000 Genomes database, or in internal database at $0.5 \%$ allele frequency. Further analysis showed that only one variant, c.7465 T > C (p. Gln2364Pro), was consistent with the phenotype of the index and shared by the three affected children in this family. Subsequent Sanger sequencing detected the same variant (p. Gln2364Pro) totally in 19 of 62 blood samples available which was not present in the HGMD or GNOMAD databases. These 19 subjects (10 females and 9 males) ranged in age from 4.1 to $60.6 \mathrm{y}$ and included 7 children $(<18 \mathrm{y} ; 3$ females, 4 males) and 12 adults (7 females, 5 males). The missense variant was predicted by in silico tools to be deleterious (Table 1). Amino acid conservation analysis showed that the affected site was highly conserved in at least fifteen species, including humans (Additional file 1: Figure S1). The three-dimensional models for aggrecan protein with the variant, produced by SWISS-MODEL SERVER (Fig. 2), showed significant anomalies in the formation of normal dimensional structure.

\section{ACAN variant and its correlation with adult height}

Among the 31 adult family members (15 females, 16 males), there were 12 adult variant carriers ( 7 females, 5 males). All of the adults with the $A C A N$ mutation had severe short stature (height $<-2 \mathrm{SD}$, Table 2), and the difference in height between members with and without the $A C A N$ variant was significant in both genders $(p<0.001$, Table 2$)$.

\section{ACAN variant and response to $\mathrm{GH}$ treatment}

The major characteristics of the three children who received GH treatment are shown in Table 1. The proband (Fig. 1, III:44) was a boy born with normal birth length and weight. However, his father's height was $153 \mathrm{~cm}(-5.36$ SDS $)$ and his mother's height was $140 \mathrm{~cm}(-2.33 \mathrm{SDS})$. He was referred to us at the age of $6.4 \mathrm{y}$ with height $100.5 \mathrm{~cm}$ (-3.74 SDS). After GH therapy, $60 \mu \mathrm{g} / \mathrm{kg} / \mathrm{d}$ for 8 years, his height was -3.75 SD below average, at latest evaluation (age 14.1 y, Fig. 3c).

The affected relative 1 in the family was a girl (Fig. 1. IV:23), born full term, with normal birth length and weight. She was referred to our clinic at the age of $5.6 \mathrm{y}$ with height $104.5 \mathrm{~cm}(-2.09$ SDS) and bone age (BA) $6.5 \mathrm{y}$. Her father's height was $170 \mathrm{~cm}(-0.44 \mathrm{SDS})$, and her mother's height 
was $138 \mathrm{~cm}$ (-4.19 SDS). Radiographs showed slight abnormalities of her spine, including cervical-vertebral clefts and apophyses in the upper and lower thoracic vertebrae (Additional file 2: Figure S2). We started GH treatment at dose $40 \mu \mathrm{g} / \mathrm{kg} / \mathrm{d}$, and she received GnRHa for pubertal management at age 7. Her height was -1.07 SDS at her latest visit (age $9.5 \mathrm{y}$, Fig. 3a).

Relative 2 (Fig. 1. IV:21) was a boy born with normal birth length and weight at full term. He visited our department at the age of $7.8 \mathrm{y}$ with height $122.5 \mathrm{~cm}(-0.88 \mathrm{SDS})$. His father's height was $150 \mathrm{~cm}$ (-3.72 SDS), and his mother's height was $160 \mathrm{~cm}(-0.11$ SDS). His bone age (BA) was $9.5 \mathrm{y}$ at his first visit. He received GH therapy, $50 \mu \mathrm{g} / \mathrm{kg} / \mathrm{d}$ (Fig. 3b). He received GnRHa at $12.2 \mathrm{y}$ due to his pubertal development. His latest height was $-0.31 \mathrm{SD}$ (at age 12.8 y, Fig. 3b).

\section{Responses to GH treatment reported in other studies}

In addition to reporting on our current cases, we reviewed the two other available studies on children with an $A C A N$ variant, which involved 18 patients. The characteristics of these patients and their responses to $\mathrm{GH}$ treatment are shown in Table 3. The change in height SDS during the first year of treatment ranged from - 0.5 SDS to 0.8 SDS, and the overall yearly height change during GH treatment was - 0.5 SDS to 0.9 SDS. Among these children, there was a general trend of a gradual reduction in yearly height SDS growth over the course of GH treatment (Fig. 4).

\section{Discussion}

Human height is a highly heritable trait that involves many genes [22]. In this study, we identified a novel $A C A N$ gene pathogenic variant $(\mathrm{c} .7465 \mathrm{~T}>\mathrm{C})$ and found that mean adult height was $-5.2 \pm 0.7$ SDS and $-3.9 \pm 0.9$ SDS in male and female variant carriers, respectively. Studies of human mating preferences with respect to height have found that short men prefer small height differences [23]; therefore, in the family studied here,
Table 1 Characteristics of children with ACAN variant treated with growth hormone

\begin{tabular}{llll}
\hline & Relative 1 & Relative 2 & Proband \\
\hline Gender & Female & Male & Male \\
Birth weight $(\mathrm{kg})$ & 3 & 3 & 3.5 \\
Birth height $(\mathrm{cm})$ & 50 & 51 & 50 \\
ACAN mutation & c.7465 T > C & c.7465 T > C & c.7465 T > C \\
Protein changes & p.Gln2364Pro & p.Gln2364Pro & p.Gln2364Pro \\
First visit & & & \\
Age (y) & 5.6 & 7.8 & 6.4 \\
Height (cm) & 104.5 & 122.5 & 100.5 \\
HSDS & -2.09 & -0.88 & -3.74 \\
Weight (kg) & 18 & 25 & 17.5 \\
BMI (kg/m ${ }^{2}$ ) & 16.48 & 16.66 & 17.33 \\
Peak growth hormone & 12.1 & ND & 15.1 \\
(ng/ml) & & & \\
IGF1(ng/ml) & 290 & 200 & 148 \\
IGFBP3 ( $\mu$ g/ml) & 4.15 & 7.96 & 3.43 \\
Bone age (y) & 6.5 & 9.5 & 6 \\
\hline
\end{tabular}

HSDS height standard deviation scores, BMI body mass index, IGF1 insulin-like growth factor 1, IGFBP3 insulin-like growth factor binding factor 3, ND not detected; ${ }^{a}$ in silico prediction: Sift: affect protein function (score $=0.00$ ); Polyphen: probably damaging $($ score $=1)$

the shortness of both parents might cumulatively affect the heights of their descendants. Our current study of a large family provides the first evidence from a Chinese population that an $A C A N$ gene variant can cause low adult height in the absence of a high incidence of familiar bone malformation.

$A C A N$ encodes aggrecan, which is the main proteoglycan in the extracellular matrix (ECM) of cartilage [24]. Aggrecan binds chondroitin sulfate and keratan sulfate to its central region, and it forms large aggregates with hyaluronan polymer through its N-terminal globular domain (G1) to form the cartilage ECM scaffold [25]. Aggrecan has two additional

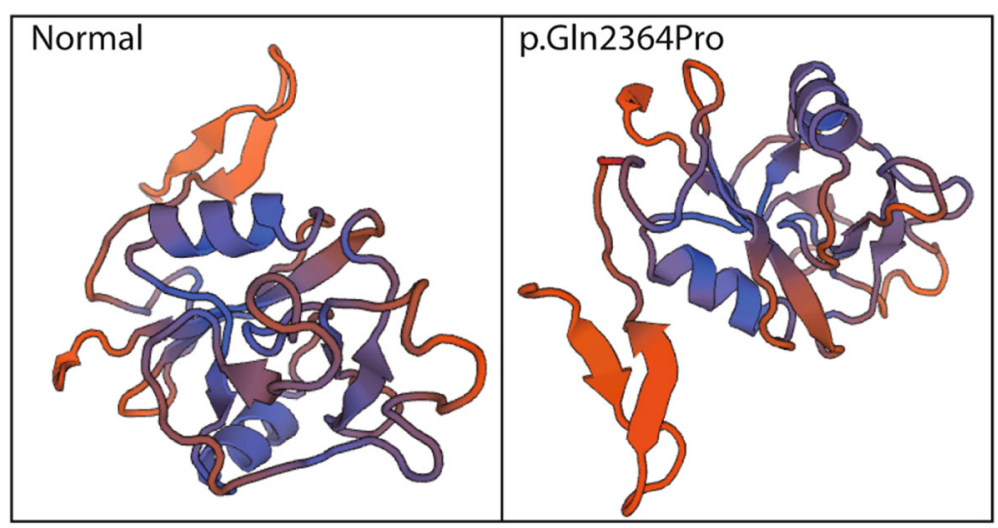

Fig. 2 The three-dimensional models for aggrecan protein with and without the variant 
Table 2 Adult heights of family members with and without ACAN variant

\begin{tabular}{llll}
\hline & Variant $(+)$ & Variant $(-)$ & $P$ value \\
\hline Male & $(n=5)$ & $(n=11)$ & \\
Height $(\mathrm{cm})$ & $141.2 \pm 4.4$ & $162.2 \pm 8.1$ & $<0.0001$ \\
HSDS & $-5.2 \pm 0.7$ & $-1.7 \pm 1.3$ & \\
Female & $(n=7)$ & $(n=8)$ & \\
Height $(\mathrm{cm})$ & $139.4 \pm 4.9$ & $156.0 \pm 5.8$ & $<0.0001$ \\
HSDS & $-3.9 \pm 0.9$ & $-0.9 \pm 1.1$ & \\
\hline Data are presented as mean + SD. HSDS height standard deviation score
\end{tabular}

globular domains (G2 and G3) that flank its central region. The G3 domain contains a C-type lectin-binding domain that is important in interactions with other extracellular proteins [25]; the function of the G2 domain is unknown. Although aggrecan dysfunction is strongly associated with chondropathy and distinct phenotypes, only a few patients with aggrecan deficiency have been reported, likely due to the wide phenotypic spectrum of ACAN mutations [26]. Patients with aggrecan mutations can remain undiagnosed owing to their presentation of clinically less significant conditions, such as ISS [4, 12, 26, 27]. Some studies have identified $A C A N$ mutations among patients with syndromic short stature conditions such as spondyloepiphyseal dysplasia, Kimberley type, short stature with early-onset osteoarthritis and/or osteochondritis dissecans [28-30]; short stature might be the most obvious manifestation of $A C A N$ mutations [26]. A recent study showed that $A C A N$ nonsense mutations are associated with short stature without advanced bone age among Chinese individuals [12]. This evidence and the findings of our study suggest that environmental factors or other undetected genetic variations also influence the manifestations of patients with $A C A N$ mutations.

To date, 25 pathogenic $A C A N$ mutations have been reported in 24 families with the dominant form of short stature $[11,12,26]$. The reported mutations were present in all domains of the gene; however, all of the mutations disrupted the integrity of at least one of the aggrecan globular domains (G1, G2 or G3) [26]. The association between $A C A N$ mutations and adult height suggests that these $A C A N$ mutations impair chondrogenesis in a similar way. In mice, aggrecan deficiency follows a recessive pattern, and homozygous deletion of aggrecan is perinatally lethal $[31,32]$. Similarly, in humans, the homozygous missense mutation (p. Asp2267Asn) in ACAN causes extreme short stature and skeletal dysplasia [30], whereas patients heterozygous for the mutation have less severe phenotypes. It is likely that the impairment of growth plate chondrogenesis is due to insufficient function rather than gain-of-function.

Considering the progressive development of short stature among patients with ACAN mutations [25],

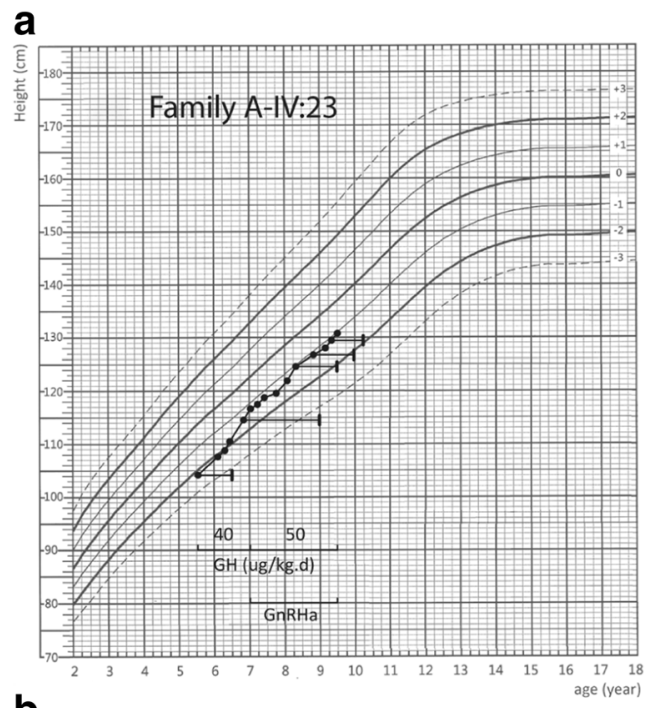

b

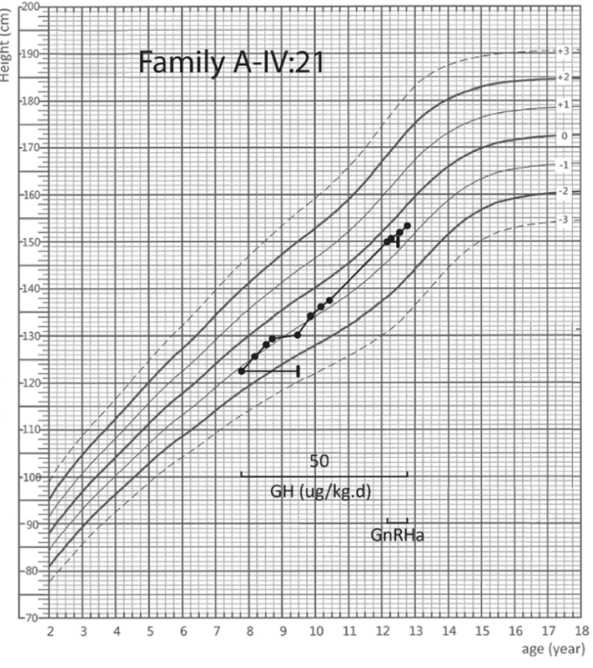

C

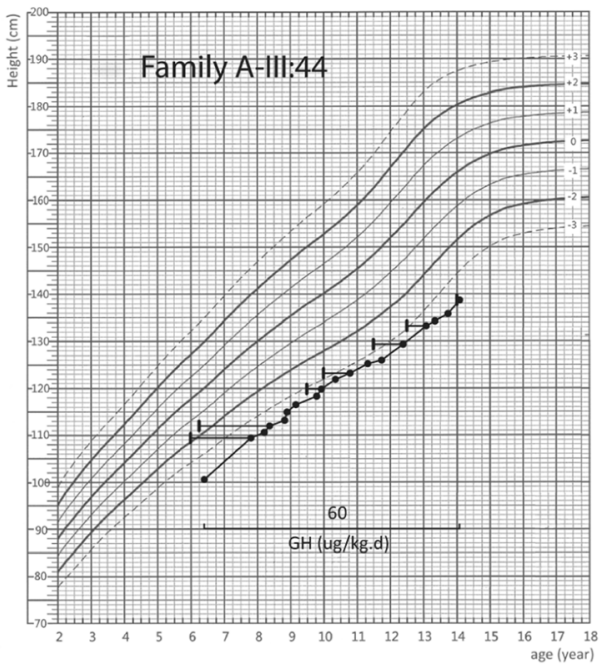

Fig. 3 Growth charts of patients with the ACAN p. GIn2364Pro variant. Vertical bars represent bone age. GH; growth hormone. GnRHa; gonadotropin releasing hormone analog 


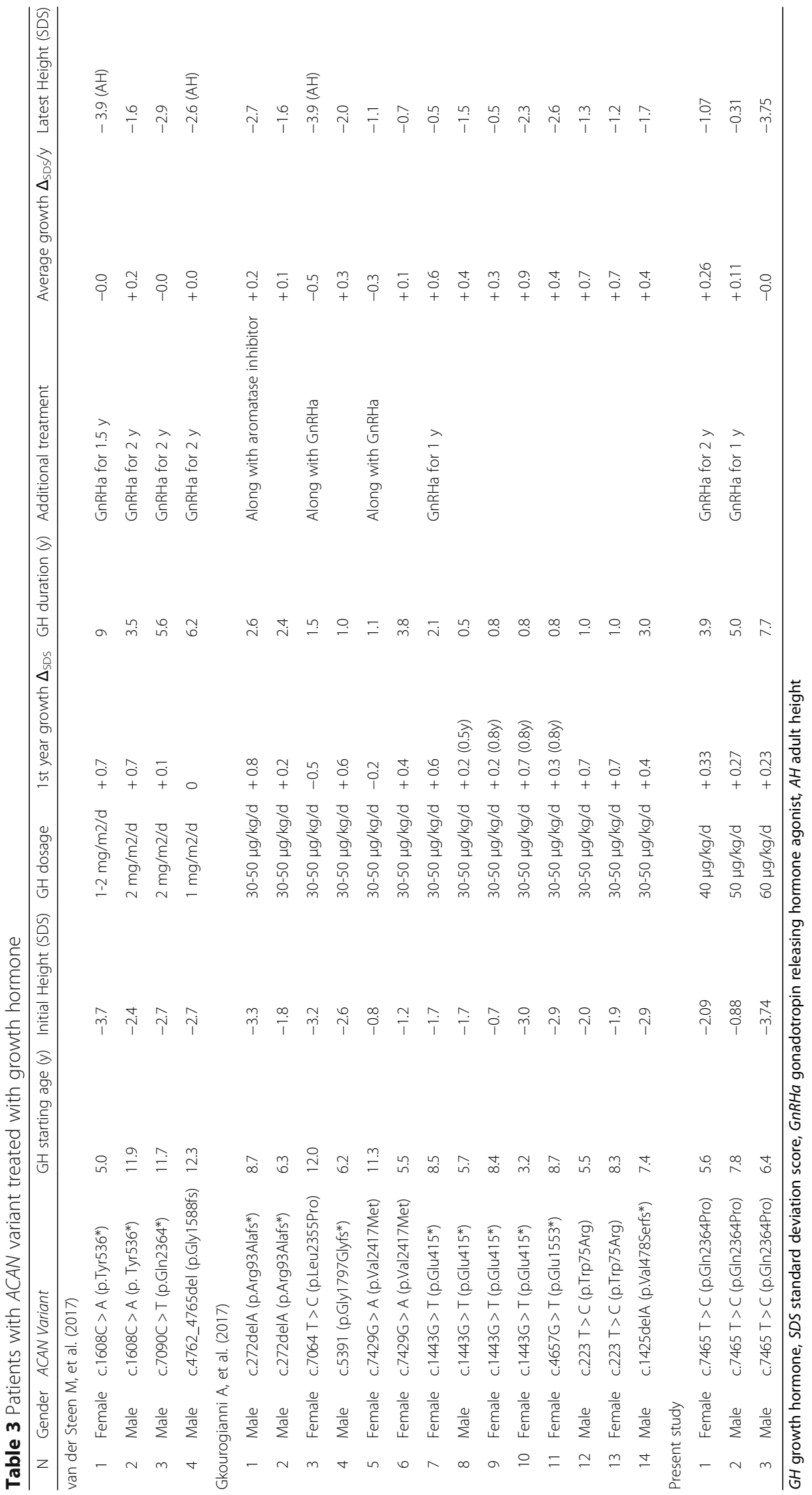




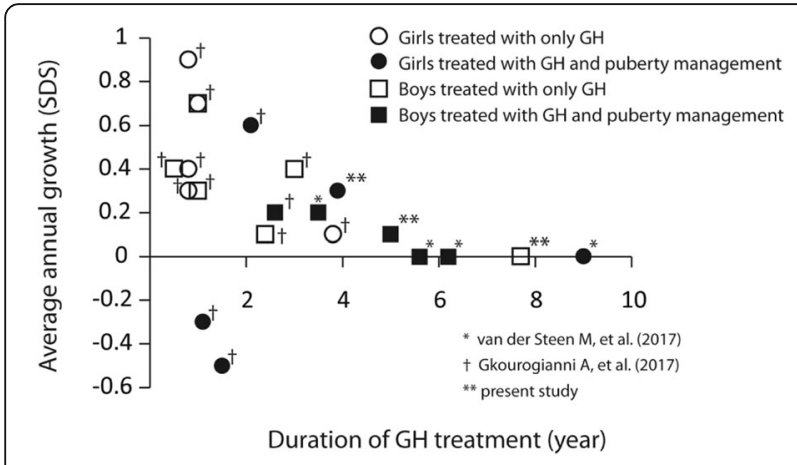

Fig. 4 Average annual change in the SDS of height in subjects with ACAN p. Gln2364Pro variant receiving GH treatment

GH-based treatment is used to rescue height deficiency and prevent further height loss. We found that, among patients with $A C A N$ mutations, the response to $\mathrm{GH}$ treatment during the first year was generally poor and was correlated with the overall response to $\mathrm{GH}$ treatment; however, patients with $A C A N$ mutations treated with $\mathrm{GH}$ were $5-8 \mathrm{~cm}$ taller than their same-sex family members [11]. GH promotes height development by stimulating IGF-1 production and chondrocyte differentiation; therefore, aggrecan deficiencies are unlikely to be repaired by $\mathrm{GH}$ alone. Future research to identify molecules to restore normal ECM is needed to improve treatment options for children with $A C A N$ mutations.

\section{Conclusions}

We have identified a novel variant in the $A C A N$ gene associated with minor bone abnormality without a high incidence of familiar bone malformation. Response to GH therapy was poor compared with the effect in GHD children; however, our results and those of other studies support the view that long-term GH therapy is beneficial for preventing age-accompanied cumulative deterioration of growth loss. Earlier genetic diagnosis and long-term therapy would be useful to obtain better clinical outcomes for children with $A C A N$ mutations.

\section{Additional files}

Additional file 1: Figure S1. The amino acid "Q" in red represents the conservative property in position "p. Gln2364Pro" among differet species. (PDF $416 \mathrm{~kb}$ )

Additional file 2: Figure S2. Black arrow: Cervical-vertebral cleft in the spine. White arrows: Apophyses in the upper and lower thoracic vertebrae. (PDF $2309 \mathrm{~kb})$

\section{Abbreviations}

BA: Bone age; BMI: Body mass index; BWA: Burrows-wheeler aligner; ECM: Extracellular matrix; GH: Growth hormone; GHD: Growth hormone deficiency; HGMD: Human gene mutation database; IGFBP3: IGF-binding protein 3; ISS: Idiopathic short stature; OMIM: Online Mendelian inheritance in man; SDS: Standard deviation score; SGA: Small gestational age

\section{Acknowledgments}

We are grateful to all of the family members for their valuable contribution to the study. We are also grateful to Professor David Josephy from the Department of Molecular \& Cellular Biology, College of Biological Science, University of Guelph, Canada, for the revision of this manuscript. The authors thank all of the physicians, nurses, and technicians involved for their assistance.

\section{Funding}

Feihong Luo is supported by Minhang District Talented Development Foundation and the Development Project of Shanghai Peak Disciplines-Integrated Chinese and Western Medicine. The study is supported by Shanghai Key Laboratory of Birth Defect, Children's Hospital of Fudan University new development project (2014-2015).

\section{Availability of data and materials}

The datasets used and/or analysed during the current study are available from the corresponding author on reasonable request.

\section{Authors' contributions}

FHL conducted clinical diagnosis and management of the patients, reviewed the data and manuscript, and was the guarantor of the work. DDX performed genetic testing and contributed to writing the manuscript. CJS performed the literature search, conducted data synthesis and reviewed the manuscript. ZYZ performed the Sanger sequencing and contributed to manuscript writing. BBW, LY and ZC conducted genetic analysis. MYZ, LX, RQC and JWN helped manage the patients and reviewed the manuscript. All authors read and approved the final manuscript.

\section{Ethics approval and consent to participate}

The study was approved by the Hospital Ethics Committee in Children's Hospital of Fudan University(No. 2010-2-26, 2012-130). The study conforms to the principles of the Declaration of Helsinki. Informed consent from participants (in the cases of children, from their parents), was obtained using an institutional consent form.

\section{Consent for publication}

Written informed consent for publication of their clinical details and/or clinical images was obtained from the patient/parents of the patients who were minors. Copies of the consent forms are available for review by the Editor of this journal.

\section{Competing interests}

The authors have nothing to disclose.

\section{Publisher's Note}

Springer Nature remains neutral with regard to jurisdictional claims in published maps and institutional affiliations.

\section{Author details}

'Department of Pediatric Endocrinology and Inherited Metabolic Diseases, Children's Hospital of Fudan University, 399 Wan Yuan Road, Minhang District, Shanghai 201102, China. ${ }^{2}$ College of Letters and Science, University of California, Berkeley, USA. ${ }^{3}$ Pediatrics Research Institute, Children's Hospital of Fudan University, Shanghai, China.

Received: 22 December 2017 Accepted: 23 April 2018 Published online: 16 May 2018

\section{References}

1. Argente J. Challenges in the Management of Short Stature. Horm Res in Paediatr. 2016;85:2-10

2. Cohen P, Rogol AD, Deal CL, Saenger P, Reiter EO, Ross JL, Chernausek SD, Savage MO, Wit JM, I.S.S.C.W. participants. Consensus statement on the diagnosis and treatment of children with idiopathic short stature: a summary of the growth hormone research society, the Lawson Wilkins pediatric Endocrine Society, and the European Society for Paediatric Endocrinology Workshop. J Clin Endocrinol Metab. 2008:93:4210-7.

3. Grimberg A, DiVall SA, Polychronakos C, Allen DB, Cohen LE, Quintos JB, Rossi WC, Feudtner C, Murad MH. Drug and therapeutics committee and ethics Committee of the Pediatric Endocrine Society. Guidelines for growth 
hormone and insulin-like growth factor-I treatment in children and adolescents: growth hormone deficiency, idiopathic short stature, and primary insulin-like growth factor-I deficiency. Horm Res Paediatr. 2016;86:361-97.

4. Quintos JB, Guo MH, Dauber A. Idiopathic short stature due to novel heterozygous mutation of the aggrecan gene. J Pediatr Endocrinol Metab. 2015;28:927-32.

5. Shima H, Tanaka T, Kamimaki T, Dateki S, Muroya K, Horikawa R, Adachi M, Naiki Y, Tanaka H, Mabe H, et al. Japanese. Systematic molecular analyses of SHOX in Japanese patients with idiopathic short stature and Leri-Weill dyschondrosteosis. J Hum Genet. 2016;61:585-91.

6. Caliebe J, Broekman S, Boogaard M, Bosch CA, Ruivenkamp CA, Oostdijk W, Kant SG, Binder G, Ranke MB, Wit JM, Losekoot M. IGF1, IGF1R and SHOX mutation analysis in short children born small for gestational age and short children with normal birth size (idiopathic short stature). Horm Res Paediatr. 2012;77:250-60.

7. Khetarpal P, Das S, Panigrahi I, Munshi A. Primordial dwarfism: overview of clinical and genetic aspects. Mol Genet Genomics : MGG. 2016:291:1-15.

8. Alatzoglou KS, Dattani MT. Genetic causes and treatment of isolated growth hormone deficiency-an update. Nat Rev Endocrinol. 2010;6:562-76.

9. Baron J, Savendahl LF, De L, Dauber A, Phillip M, Wit JM, Nilsson O. Short and tall stature: a new paradigm emerges. Nat Rev Endocrinol. 2015;11:735-46.

10. Baron J, Savendahl L, De Luca F, Dauber A, Phillip M, Wit JM, Nilsson O. Short stature, accelerated bone maturation, and early growth cessation due to heterozygous aggrecan mutations. The J Clin Endocrinol Metab. 2014;99:E1510-8.

11. van der Steen M, Pfundt R, Maas S, Bakker-van Waarde WM, Odink RJ, HokkenKoelega ACS. ACAN gene mutations in short children born SGA and response to growth hormone treatment. J Clin Endocrinol Metab. 2017;102:1458-67.

12. Hu X, Gui B, Su J, Li H, Li N, Yu T, Zhang Q, Xu Y, Li G, Chen Y, Qing Y, Chinese Genetic Short Stature, Consortium, Li C, Luo J, Fan X, Ding Y, Li J, Wang J, Wang $X$, Chen S, Shen Y. Novel pathogenic ACAN variants in non-syndromic short stature patients. Clin Chim Acta. 2017;469:126-9.

13. Li H, Ji CY, Zong XN, Zhang YQ. Height and weight standardized growth charts for Chinese children and adolescents aged 0 to 18 years]. [Article in Chinese. Zhonghua Er Ke Za Zhi (Chinese J Pediatr). 2009;47:487-92.

14. Patel L, Clayton PE. Predicting response to growth hormone treatment. Indian J Pediatr. 2012;79:229-37.

15. Wang K, Li M, Hakonarson H. ANNOVAR: functional annotation of genetic variants from high-throughput sequencing data. Nucleic Acids Res. 2010;38:e164.

16. McLaren W, Pritchard B, Rios D, Chen Y, Flicek P, Cunningham F. Deriving the consequences of genomic variants with the Ensembl API and SNP effect predictor. Bioinformatics. 2010;26:2069-70.

17. Kumar P, Henikoff S, Ng PC. Predicting the effects of coding non-synonymous variants on protein function using the SIFT algorithm. Nat Protoc. 2009;4:1073-81.

18. Adzhubei IA, Schmidt S, Peshkin L, Ramensky VE, Gerasimova A, Bork P, Kondrashov AS, Sunyaev SR. A method and server for predicting damaging missense mutations. Nat Methods. 2010;7:248-9.

19. Schwarz JM, Rodelsperger C, Schuelke M, Seelow D. MutationTaster evaluates disease-causing potential of sequence alterations. Nat Methods. 2010;7:575-6.

20. Pollard KS, Hubisz MJ, Rosenbloom KR, Siepel A. Detection of nonneutral substitution rates on mammalian phylogenies. Genome Res. 2010;20:110-21.

21. Biasini M, Bienert S, Waterhouse A, Arnold K, Studer G, Schmidt T, Kiefer F, Cassarino TG, Bertoni M, Bordoli L, Schwede T. SWISS-MODEL: modelling protein tertiary and quaternary structure using evolutionary information. Nucleic Acids Res. 2014:42:W252-8.

22. Wit JM, Oostdijk W, Losekoot M, van Duyvenvoorde HA, Ruivenkamp CA, Kant SG. Mechanisms in endocrinology: novel genetic causes of short stature. Eur J Endocrinol. 2016;174:145-73.

23. Stulp G, Buunk AP, Pollet TV, Nettle D, Verhulst S. Are human mating preferences with respect to height reflected in actual pairings? PLoS One. 2013;8:e54186

24. Sophia Fox AJ, Bedi A, Rodeo SA. The basic science of articular cartilage: structure, composition, and function. Sports health. 2009;1:461-8.

25. Aspberg A. The different roles of aggrecan interaction domains. J Histochem Cytochem. 2012;60:987-96.

26. Gkourogianni A, Andrew M, Tyzinski L, Crocker M, Douglas J, Dunbar N, Fairchild J, Funari MF, Heath KE, Jorge AA, et al. Clinical characterization of patients with autosomal dominant short stature due to Aggrecan mutations. J Clin Endocrinol Metab. 2017;102:460-9.

27. Dateki S, Nakatomi A, Watanabe S, Shimizu H, Inoue Y, Baba H, Yoshiura KI, Moriuchi $\mathrm{H}$. Identification of a novel heterozygous mutation of the
Aggrecan gene in a family with idiopathic short stature and multiple intervertebral disc herniation. J Hum Genet. 2017;62:717-21.

28. Gleghorn $L$, Ramesar $R$, Beighton $P$, Wallis $G$. A mutation in the variable repeat region of the aggrecan gene (AGC1) causes a form of spondyloepiphyseal dysplasia associated with severe, premature osteoarthritis. Am J Hum Genet. 2005;77:484-90

29. Stattin EL, Wiklund F, Lindblom K, Onnerfjord P, Jonsson BA, Tegner Y, Sasaki T, Struglics A, Lohmander S, Dahl N, Heinegard D, Aspberg A. A missense mutation in the aggrecan C-type lectin domain disrupts extracellular matrix interactions and causes dominant familial osteochondritis dissecans. Am J Hum Genet. 2010;86:126-37.

30. Tompson SW, Merriman B, Funari VA, Fresquet M, Lachman RS, Rimoin DL, Nelson SF, Briggs MD, Cohn DH, Krakow D. A recessive skeletal dysplasia, SEMD aggrecan type, results from a missense mutation affecting the C-type lectin domain of aggrecan. Am J Hum Genet. 2009:84:72-9.

31. Watanabe H, Kimata K, Line S, Strong D, Gao LY, Kozak CA, Yamada Y. Mouse cartilage matrix deficiency ( $\mathrm{cmd}$ ) caused by a $7 \mathrm{bp}$ deletion in the aggrecan gene. Nat Genet. 1994;7:154-7.

32. Lauing KL, Cortes M, Domowicz MS, Henry JG, Baria AT, Schwartz NB. Aggrecan is required for growth plate cytoarchitecture and differentiation. Dev Biol. 2014;396:224-36.

\section{Ready to submit your research? Choose BMC and benefit from:}

- fast, convenient online submission

- thorough peer review by experienced researchers in your field

- rapid publication on acceptance

- support for research data, including large and complex data types

- gold Open Access which fosters wider collaboration and increased citations

- maximum visibility for your research: over $100 \mathrm{M}$ website views per year

At BMC, research is always in progress.

Learn more biomedcentral.com/submissions 